\title{
Construction of green building material management system based on BIM Technology
}

\author{
ZhiNeng Tong \\ Jiangxi Normal University of science and technology ,China
}

\begin{abstract}
Keywords: BIM technology, BIM model, information data.
Abstract: China's current green building materials management is imperfect, there are still many shortcomings. Actively building green building materials management system based on BIM technology, combined with the characteristics of green building materials and its relationship with BIM technology, it is urgent to better realize the management of green building materials.

In the current social development and construction, the establishment of environment-friendly and resource-saving society is of great significance. In this process, the development of green building is essential. The prerequisite for the realization of green building development is to strengthen the management of green building materials, and to ensure that building materials are comfortable, economical, healthy, energy saving, environmental friendly and other green features. At present, China's green building materials for the development and research in the "four sections of an environmental protection" stage, the green building design and construction also put forward higher requirements. However, there are still some problems and shortcomings in the construction of green building materials management system.
\end{abstract}

\section{Management characteristics of green building materials}

First of all, manufacturers of green building materials should clearly recognize the standards of green building materials, and strictly manage the green degree in the process of production. At the same time, in accordance with the actual needs of different green buildings, green building materials with different green levels can be supplied, and the management of inventory, sales volume and production capacity shall be strengthened. Then, as green building materials come in many different categories and projects, it will involve many different material suppliers and manufacturers.

So in the green building materials management, the traditional management mode of building materials are too extensive, have been difficult to meet the current needs of [1]. management in this regard, take the fine management mode of management of green building materials, it is necessary to. Finally, in the actual construction of green building, according to the actual requirements of architectural design, different types of green building materials should be chosen. All parties involved in the construction of the project and their upstream and downstream enterprises should pay attention to strengthening coordination and communication. After the completion of the project delivery, shall provide the corresponding information of green materials and green building information to the property side, so that helps the property side in the days after the use of green materials for maintenance or replacement and maintenance.

\section{Relationship between BIM technology and green building material management characteristics}

\section{Traceability of information}

In the actual use of green building, combined with the specific requirements of functional use, you can adjust, replace and maintain the corresponding green building materials. Therefore, in the process of operation and management of green building, it is very important to the construction of green building materials, application materials, material production function parameter information such as the history of engineering information[2]. And the construction process of green building in the design, BIM technology can accurately record the green building materials information and detailed 
engineering information. At the same time, it can also record the occurrence of engineering changes in detail, and accurately evaluate the green grade of green buildings.

\section{Collaborative management}

In the process of the construction of green projects, green building materials manufacturers and suppliers, construction units, design units, the owners should be collaborative management of project construction material, which can form an industrial chain. Materials manufacturers, suppliers, construction units, the owners shall actively participate in the green building design stage, the value of individual demand of reasonable formulation, so as to clear the production and green building materials, green building construction scheme and provide technical measures. The application of green building materials in green building puts forward higher cooperative management requirements for all parties involved in the project.

\section{Fine management}

Green building materials in construction, maintenance, operation, construction, design and other stages, all need to build a fine library of information. In this way, the parties involved in the green building project can be more accurate production, use, ordering and query of green building materials, resulting in the use and management of green building materials fine practical application in the process of. In the process of building the information base of green building materials, BIM technology can play a great role in the process of maintenance, use and production of green building materials, and realize fine management. In addition, the information breach of green building materials management will be broken, and the parties involved in the project can share the information better.

\section{D visualization}

In the process of green building design and construction, through the establishment of three-dimensional model, can provide visual simulation to the customer, make it more intuitive understanding and understanding of the project. The 3D visualization model characterized by its intuitive, in green materials and other site management, construction design, green material selection, green building apartment layout design and other aspects can, play a great role in the [3]. green building project, the establishment of three-dimensional model of green building materials and construction, also need to BIM technical support.

\section{Construction of green building material management system based on BIM Technology}

\section{composition of green building material management system}

\section{Application management layer}

In the three-dimensional model based on BIM technology, the application of management role is to manage green building materials, construction and design, green building projects and other aspects of the model. And in the use and maintenance of green building on the management, use the corresponding maintenance information and historical information traceability. In the green building life cycle, through the three-dimensional model based on BIM technology, the project participants can parameter information for green building materials for accurate extraction, in order to better communication and information sharing, unified and effective integration of management resources, developing better project management decision.

\section{Data exchange layer}

In the whole life cycle of green building, green building materials to achieve collaborative management through the BIM technology, the network information transmission platform and cloud services platform is built, which can effectively manage and share information. In addition, in the BIM technology data exchange process, the handset, the notebook and so on the terminal equipment provided the good hardware support for it.

\section{BIM model layer}

Before the construction of green building construction, construction units, design units, the owners shall advance the purchase of green building materials, and to make a comparison between the different simulation models were completed, with the development of construction technology and construction 
scheme. Therefore, in the application of BIM model in green building material management system, more attention has been paid to the construction of technical model, material model, material database and so on. According to the actual demand of green building materials management, in the model layer, the core of BIM model were set up, which makes the whole life cycle of green building, green building materials are able to achieve the perfect management.

\section{Basic data layer}

In the process of the management of green building materials, it concerns the function and production information of green building materials, architectural framework design model information, green building materials evaluation information and so on. Therefore, in the construction of green building materials management system based on BIM technology, IFC format should be used to convert and store data, and to manage BIM basic data uniformly in the same platform. After the completion and acceptance of the project, the operation and maintenance of the later stage needs the BIM information database to provide relevant information, so as to form a cycle feedback, and provide relevant reference for other construction projects. So rich, huge BIM database, for the state, industry, enterprises in the green building materials management level has a great role in promoting.

\section{Implementation of green building material management system}

\section{Production and transportation of materials}

The RFID tag will be attached to the green building materials that have just been shipped. The green building materials will be scanned through the reader and then uploaded to the BIM to achieve the management of green building materials. Thus, in the management of green building materials, material suppliers and manufacturers can achieve zero inventory and zero defects. In the process of material transportation, the order, route and train number of transportation are optimized on the basis of visualization model and storage area.

\section{Material construction}

Storage and lifting of materials, RFID tags can be used for tracking and monitoring, management of materials access construction. Through the cloud platform for the transmission of these information, to avoid the artificial input of information arising from negligence or error. For example, in the process of material access check, you can use RFID reader to automatically collect data to manage the material.

\section{Material operation}

The RFID tag also contains material maintenance information, which allows rapid location of material and storage of maintenance records in the RFID tag. In addition, it can also integrate maintenance information in the BIM property management system, thus more intuitive management and maintenance of green building materials.

\section{Material removal}

When the construction project reaches the life cycle, the green building materials can be recycled and used at the time of demolition, and the BIM database and RFID tags can be used to judge. This can better realize the recycling management green building materials, play a role in saving resources and reducing consumption, so as to better realize the green development of construction projects.

\section{Conclusion}

In the current society, people pay more and more attention to the green environmental protection of buildings. Green building material is the important condition and foundation to realize the greening of building project. However, China's current management of green building materials is not perfect, there are still many deficiencies. In this regard, we should actively build green building materials management system based on BIM technology, combined with the characteristics of green building materials and its relationship with BIM technology, so as to better realize the management of green building materials. 


\section{References}

[1] Cheng Yuan cheng. Application Research of green building design based on BIM technology [D]. Hunan University, 2013.

[2] Wang Zhenshuang, Wang Liguo, Gaoping, Chen Xiaobo. Research on green building materials management system based on BIM technology [J]. building economy, 2015,04: 83 -86.

[3] Guo Yunpeng. Study on the application strategy of BIM technology in green building life cycle [D]. Harbin Institute of Technology, 2013.

[4] Kang Ming, Zhang Hao. Discussion on the application of environmental protection and energy saving design in green building [J]. Building materials and decoration (early part). Marketing, 2010.4 (10): 23 - 24. 